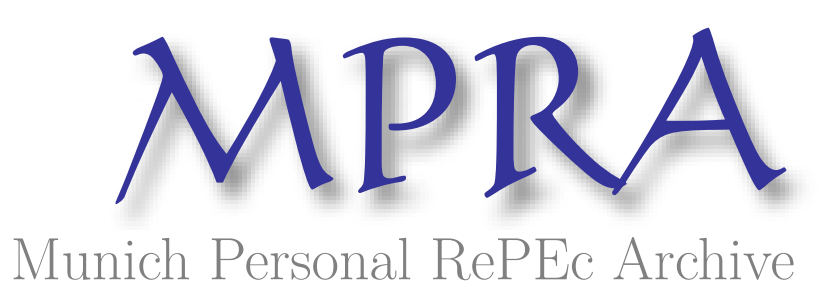

\title{
Asset pricing and predictability of stock returns in the french market
}

Ellouz, Siwar and Bellalah, Mondher

Paris Dauphine

7 March 2007

Online at https://mpra.ub.uni-muenchen.de/4961/

MPRA Paper No. 4961, posted 18 Sep 2007 UTC 


\section{ASSET PRICING AND PREDICTABILITY OF STOCK RETURNS IN THE FRENCH MARKET ${ }^{*}$}

\section{Mondher Bellalah}

Professor, searcher

Work:

University of Cergy,

33 boulevard du Port,

95310 Cergy France

Phone: 0134256063

Fax: 0134256233

E-mail: Bellalah@u-cergy.fr

\section{Siwar Ellouz}

Student, searcher

work:

University of Paris-Dauphine and

FSEG SFAX (Tunisia)

\section{Residence:}

Adresse: 21 Rue Taher Sfar Sfax (3000)

Phone : (00216)96003966

E-mail: Ellousiw@yahoo.fr

\footnotetext{
* We thank the professor Fathi ABID for his interesting suggestions for this paper and we thank all the participants in the international conference IFC4 (Mars 2007), where this work has be presented and discussed.
} 


\title{
ASSET PRICING AND PREDICTABILITY OF STOCK RETURNS IN THE FRENCH MARKET
}

\begin{abstract}
This paper studies the predictability of returns in the French stock market. It provides an analysis of predictable components of monthly common stock returns.

We study a single-beta conditional model and we show that stock market risk premium is variable over the time and is important for capturing predictable variations of stock returns. We find also that the expected excess returns on small and medium capitalization stocks are more sensitive to changes in the predetermined variables such as dividend yields, default spread and term spread, than expected excess returns on large capitalization stocks.
\end{abstract}

Key words: predictability, predetermined variables, conditional asset pricing, stock returns. 


\section{ASSET PRICING AND PREDICTABILITY OF STOCK RETURNS}

\section{IN THE FRENCH MARKET}

\section{Introduction}

The predictability of stock returns is an interesting subject of debate in the recent financial literature. It is an issue that attracts enormous focus of researchers because of its theoretical importance and practical implications. Predictability is related to the possibility of generating an excess returns in using past information.

The sources of the predictability of stock returns are well documented. Indeed, there are two competing point of views. The first one considers that predictability is attributed to market inefficiencies and the second argues that predictability is the result of variation in the expected returns driven by economic fundamentals. The rational expectations theory has as a consequence that expected stock returns should be predictable if they are related to the predetermined variables, which predict the variation over the time. Bekaert (2001) stipulates that predictability may also reflect irrational behaviour on the part of market participants or should be the result of poor statistical inference.

The asset pricing models make a relation between expected returns and their sensitivity to changes in the economic factors, or factor loadings (the betas coefficients). The price of the beta is measured by a risk premium. So that, the predictable variation of stock returns, can be attributed to the changes in the betas, in the risk premium or in both of them.

Recently, a large number of studies in the finance literature have confirmed the evidence of the predictability of stock returns by means of interest rates, dividend yields and variety of macroeconomic variables reflecting business cycle variations.

Ferson and Harvey (1991) explain the evidence of the predictability by standard risk factors in a multiple beta model. They identify the prespecified economic factors used by Chen, Roll, and Ross (1986) and find that risk premiums vary over the time and are higher during the recessionary period. Summers (1986) find that the logarithm of stock price index can be described by a component of random walk and a component of stationary mean reverse. Shiller and Perron (1985), Poterba and Summers (1986) suggest a similar models with an alternative hypothesis which stipules that investors are irrationals.

However, Lo and McKinley (1988) reject the postulate of random walk and mean reverse with American data.

The most significant variables used in American studies are the past returns of stock market, the dividend rate of a market index, the earning to price ratio and variables of term structure. 
Fama (1981) find that the stock returns are negatively correlated to the expected inflation and to the level of short-term interest rate. Keim and Stambaugh (1986) develop predetermined variables that are able to predict expected stock and bond returns.

Fama and French (1988 a), advance that past returns can predict $40 \%$ of future stock returns at long horizons. Fama and French (1989) suggest that the predictable variation in expected returns is rational and largely common across security classes (stocks and bonds). The predictability reflects changing in business conditions. Jagannathan and Wang (1996) argue that during a recession period, the financial leverage of firms in relative poor shape may increase comparing to the other firms. So their systematic risk (stock betas) should increase. Kothari and Shanken (1997), find that the book to market ratio have a strong ability to predict future returns. Finally, several studies, which are based on daily and weekly data, make a weak evidence of predictability using t-student statistics, $\mathrm{R}^{2}$ and $\mathrm{p}$ value.

In the other hand, the concept of stock returns predictability is often related to market efficiency and investor rationality. Balvers, Cosimano and McDonald (1990) argue that predictable movements in economy are consistent with efficient markets. However, other researchers stipulate that if stock markets are efficient, then it shouldn't be possible to predict stock returns. Nevertheless, this affirmation is not always true because the stock market returns will be not predictable only if market efficiency is combined with risk neutrality (Pesaran (2003)). Indeed, under the joint hypothesis of market efficiency and risk neutrality, returns should not be predictable. So, excess returns can be predictable at an efficient stock market if investors are risk averse. The extent to which excess returns can be predicted will depend on the presence of a stable relation between the risk premium and the predetermined variables. Rey (2004) argues that stock market predictability on its own would not imply stock market inefficiency and irrational behaviour. Indeed, we should also study the risk aversion of the investor.

This paper provides a global asset pricing perspective on the relation between instrumental or predetermined variables of common stocks and future returns. We focus on determination of attributes that are able to predict expected returns. We develop a conditional asset pricing model that include lagged attributes such as ratios of price to book, cash flow, earnings, book to market, dividend yield, etc. and we develop a time series regressions which are able to explain the time variation of stock returns over the time. Our main object is to study the predictability of stock returns in the French market. Our results are useful for future researches such as asset allocation in the presence of predictability and performance measures issues. Finally the evidence of predictability can have a determinant effect at asset pricing theory. 
This paper is organized as follows. Section II describes the model, and section III describes our methodology. Section IV describes data, while section V presents the main results of our study. Section VI focus on January effect and finally, section VII summarizes and concludes.

\section{The model}

We develop a conditional asset-pricing model with a single beta, which has the form of conditional capital asset pricing model (conditional CAPM) (see Sharpe (1964), Merton (1973), Constantinides (1980), etc.). This model attributes predictability of returns to changes in the expected compensation for risk. Theoretically, conditional CAPM could hold perfectly; that is conditional alphas are always zero but time variation in beta might lead to unconditional pricing error (see, Jensen (1968), Dybvig and Ross (1985), Jagannathan and Wang (1996), among others.)

Generally, there is evidence that an unconditional alpha of stock returns differs from zero if its beta covaries with the market premium or with the market volatility.

The model is described as follow:

$$
E\left(R_{p t} / Z_{t-1}\right)=\gamma_{0}\left(Z_{t-1}\right)+b_{p m, t-1} \gamma_{m}\left(Z_{t-1}\right)(1)
$$

Where $R_{p t}$ is the excess rate of return on the portfolio $\mathrm{p}$, between times $\mathrm{t}-1$ and $\mathrm{t} ; Z_{t-1}$ is a vector of predetermined variables of public information available at $\mathrm{t}-1 ; b_{p m t-1}$ is a conditional market beta or factor loading; $\gamma_{0}\left(Z_{t-1}\right)$ is the expected return of all portfolios with market beta equal to zero. If there is a riskless asset available at $\mathrm{t}-1$, then its rate of returns equals $\gamma_{0}\left(Z_{t-1}\right)$.

Finally, $\gamma_{m}\left(Z_{t-1}\right)$ represents the market price of systematic risk or expected risk premium. Rational expectation theory implies that current return differs from the conditional expected value by an error term, $\varepsilon_{p t}$, which is orthogonal to the information at $\mathrm{t}-1$. So that, if the current return is predictable using public information in $Z_{t-1}$, the model implies that either the beta or the premiums $\gamma_{m}\left(Z_{t-1}\right)$ and $\gamma_{0}\left(Z_{t-1}\right)$ are varying as functions of $Z_{t-1}$. 


\section{Methodology}

We develop tests based on time-series regressions of returns on the market factor and a vector of predetermined variables. This regression is described as follow:

$r_{p t}=\alpha_{p 0}+\sum_{k=1}^{L} \alpha_{p k} Z_{p, t-1}+\beta_{p} r_{m t}+\varepsilon_{p t}, \mathrm{t}=1 \ldots \mathrm{T}$

With:

$r_{p t}$ is the excess return of the portfolio $\mathrm{p}, r_{p t}=R_{p t}-R_{f t}$, where $R_{p t}$ is the return of the portfolio $\mathrm{p}$ and $R_{f t}$ is the return of one month treasury bill.

$Z_{p, t-1}$ is the value of predetermined variable $\mathrm{p}$ at $\mathrm{t}-1$

$r_{m t}$ is the excess return of the market portfolio, $r_{m t}=R_{m t}-R_{f t}$, where $R_{m t}$ is the return of market portfolio at time t.

$\beta_{p}=\operatorname{Cov}\left(r_{p}, r_{m}\right) / \operatorname{Var}\left(r_{m}\right):$ it represents the systematic risk of the portfolio $\mathrm{p}$.

\section{Hypotheses}

- The conditional betas $\beta_{p}$ are fixed parameters over time.

- $E\left(\varepsilon_{p t} / Z_{t-1}\right)=E\left(\varepsilon_{p t} r_{m t} / Z_{t-1}\right)=0$ for all $\mathrm{p}$ and $\mathrm{t}$ (the conditional expected values of term errors are equal to zero and the term of errors are independent from the explicative variables)

- $E\left(\varepsilon_{p t} \varepsilon_{p t^{\prime}} / Z_{t-1}\right)=0$ if $\mathrm{t} \neq \mathrm{t}$ ' (the term errors are not correlated)

- $E\left(\varepsilon_{p t}^{2} / Z_{t-1}\right)=\sigma_{\varepsilon}^{2}$ (The conditional variance of the term of errors is constant over the time: homoskedasticity).

- Absence of co linearity between the explicative variables.

If the lagged variables are not significant in the determination of variation on stock returns, then the model implies that $E\left(r_{p t} / Z_{t-1}\right)=\beta_{p} E\left(r_{m t}\right)$.

This model is similar to single factor latent variables model (Gibbons and Ferson (1985), Ferson (1990)). It represents also a particular case of the model developed by Ferson and Korajczyk (1995).

Our main objective in this paper is to study the ability of the model to capture the predictable variation in stock returns over the time. Consequently, we will test a joint hypothesis that $\alpha_{p 0}$ and the $\alpha_{p k}$ 's are equal to zero in (2). These tests examine whether the variation of expected stock returns are time varying with the predetermined variables. 
The rejection of the model (2) can be attributed to non-variability of the expected stock returns over the time. It can also be imputed to the non-constancy of beta or the lack of others explanatory factors or lagged variables.

Moreover, it is interesting to explain if the changes of expected returns in excess on the risk free rate (risk premiums) are assigned to changes in risk.

Recently, a large number of studies focus on predicting the time variation of risk premiums with ex ante variables. Keim and Stambaugh (1986), regress monthly risk premiums for portfolios of longterm US bonds and common stocks, on three ex ante variables (the yield variable, the S\&P variable and the small-firm variable) over the period 1928 to 1978 and find that expected risk premiums change over the time and that the levels of asset prices contain information about expected premiums. Fama and French (1989) develop multiples regressions of excess returns on the term spread (TERM), and the value-weighted dividend yield (D/P) or the default spread (DEF) over the period 1927 to 1987 and conclude that the term spread component of expected returns is less persistent than the expected return variation captured by the dividend yield and the default spread variables. Nevertheless, the regressions on the three variables show that expected risk premiums vary with ex ante variables ("expected returns are low when times are good and higher when they are poor" ${ }^{1}$ ). Ferson and Harvey (1991) find that average premium for the stock market index is not significant in the multiple-beta model. This premium is positively related to dividend yield and negatively related to the short-term bill rate. Consequently, it is important to study the effect of ex ante variables on the change of risk premiums So, we regress risk premiums of stock portfolios and market portfolio on the predetermined variables to predict their variation over the time.

- $r_{P t}=Z_{t-1}^{\prime} \gamma_{P}+\varepsilon_{1 P t}(3 \mathrm{a})$

This regression has as objective, the determination of the fraction of predictability captured by the predetermined variables.

- $r_{m t}=Z_{t-1}^{\prime} \delta_{m}+\varepsilon_{2 m t}$

This regression makes a relation between the market factor and the predetermined variables.

1 This expression is extracted from the article of Fama. E and French.K (1989), intituled "Business conditions and expected returns on stocks and bonds". Journal of financial economics 25 page 37. 


\section{The data}

\section{A. Common stock returns}

We study monthly common stock returns during the period from July 1974 to March 2004 (357 months). The stocks are of firms listed on the French stock market (first market, second market and new market ${ }^{2}$ ). In order to avoid the survivor bias in the sample, we have included the returns of dead firms stocks. So our sample is composed of 527 firms for which all the variables of our model are available. DataStream provides the data of this study.

\section{B. Information variables or predetermined attributes}

In order to measure the information that investors use to price securities in the market, we use predetermined variables. Our choice of variables is inspired from previous studies about the American stock market. We distinguish two kinds of ratios: macroeconomic ratios or attributes and valuation ratios.

\section{B.1. Macroeconomic ratios}

The evidence of predictability focus on whether there is a coherent story that relates the variation through time of expected returns on stocks to business conditions. Indeed it is proved in previous researches that predictable variation in stock returns is tracked by a set of variables commonly used to measure default and term premiums related to corporate bonds and dividend yields of stock indexes. For this reason, we select macroeconomic ratios from DataStream database and from the French central bank ${ }^{3}$. These ratios should predict the common variation of stock returns. They are defined as follow:

(1) A lagged value of the variable (TERM) which measures the term premium or the difference between the lagged long term government bond in French market extracted from DataStream and the lagged value of treasury bill discount-three months for the period 07/1974$12 / 2001$ (versus treasury bond yield on three months treasury bonds for the period 01/200203/2004 because of missing data). The choice of this variable is justified by previous studies of Fama and French (1989), Fama (1990), Ferson and Korajczyk (1995), among others which demonstrate that term premium of bond yield is able to predict future returns of stocks. Moreover, according to Fama and French (1989), there is reasonable and old hypothesis, which suggests that the term premium compensates for exposure to discount-rate shocks that affect all long-term securities stocks in approximately the same way.

(2) A lagged value of the variable (DEFAULT), which measures the default premium. It is related to quality yield spread in the corporate bond market. This variable is extracted from

DataStream. It is defined as the difference between the lagged bond market rate of second category

\footnotetext{
${ }^{2}$ «Premier marche, second marche and nouveau marche»

3 «Banque de France»
} 
bonds (FR BOND MARKET RATE ON ISSUE OR IN SETTELMENT - 2ND CATEGORY BONDS) and the lagged bond market rate of first category bonds in the French bond market (FR BOND MARKET RATE ON ISSUE OR IN SETTELMENT - 1ST CATEGORY BONDS). Keim and Stambaugh (1986) and Ferson and Korajczyk (1995) find that a default spread has some predictive power for expected bond and stock returns.

Fama and French (1989) argue that default spread and the dividend yield track components of expected returns that vary with the level or price of some business-conditions risk.

\section{B.2. Valuation ratios}

Quantitative stock selection models use widely valuation ratios for individual stocks in the United States and in other national markets (Rosenberg et al (1985), Guerard and Takano (1990), Wadhwani and Shah (1993), among others.)

Fama and French (1992, 1993, and 1996) are interested in valuation ratios to explain common variations of stock returns. Ferson and Harvey (1998) have used the valuation ratios at the country level to model cross section of conditional expected returns. At the country level, Stulz and Wasserfallen (1995) attribute the differences in valuation ratios to differences in expected returns.

We use four valuation ratios extracted from DataStream database: Dividend yield, Earning to price ratio, Price to cash earning ratio and Book to market ratio for each firm in the sample. After that, we calculate these ratios for a value weighted stock index of the French market. Our objective is to model time series conditional expected returns to predict their variation over the time.

We define lagged values of valuation ratios as follow:

(1) The dividend yield (noted DY): it expresses the dividend per share as a percentage of the share price. In our study, we use a lagged value of dividend yield of a value weighted stock index formed by all the stocks in the sample.

A lagged dividend yield is the stock index level at the end of previous month, divided into previous year's dividend payments for the index. Dividend yield is a component of the return of stocks. Consequently, it represents an information variable that is able to capture predictability of stocks returns. Campbell and Shiller (1988), Fama and French (1988 a, 1989), among others study similar variables. The dividend variable is strongly correlated with the inverse of the price level of common stocks (Keim and Stambaugh (1986)). The lagged dividend yield of the value-weighted index might be able to capture potential mean reversion in the stock market.

Mean reversion is a process implying that expected returns may be higher than average if stock returns are below average. It is the case on which prices are relatively low and yields are high. 
(2) Earning to price ratio (noted PERINV): it represents the earnings rate per share divided by the price of the stock at the required date. We use a ratio value weighted average of individual ratios, average across firms in the sample. The choice of this ratio rather than the inverse is justified by avoiding extreme outliers caused by near zero earnings. Basu (1977) has used this ratio to predict expected returns.

(3) Price to cash earning ratio (noted PCASH): it represents also the price to cash flows and is defined by DataStream data base as the price divided by the cash earnings per share for the appropriate financial year end, adjusted for capital changes. The cash earning is the earnings per share before depreciation, amortization and provisions (it is assumed to cash flows). We use a ratio of price to cash earning ratio which is a value weighted average of individual ratios. Chan and al (1991) found that the ratio of price to cash flow is much correlated to individual stock returns in Japan than a ratio of price to earning ratio. Cash is equal to earning plus depreciation.

(4) Book to market ratio (noted BTMKT): it is the inverse of the value market to book provided by DataStream database. Market to book is also called discount to net asset value and is defined as the market value divided by the net book value. We use a ratio of book to market which is a value weighted average of individual ratios. This ratio may be having an ability to predict stock returns. Fama and French (1993) used this ratio to explain expected stock returns.

\section{Empirical results}

Our sample includes all the firms listed on the French stock market and all the firms, which have dead or not listed from the market. Indeed, a firm, which has not data at future time, can be included in database at the current date. Moreover, we choose only the firms with available countable data common for each valuation ratio (Dividend yield, book to market, price to cash earning ratio and earning to price ratio). In each date, a firm is excluded if it has a zero or negative value for the particular account ratio. So 527 firms form the sample.

\section{A. Regression results and tests of predictability of stocks returns}

\section{A.1. Description of dependant variables}

Five common stock portfolios are formed according to size quintiles. To construct these portfolios, we classify the firms each year $n$, during the period from July $n$ to June $n+1$, according to their market value of June $n$. We obtain five portfolios of size, which are value weighted each month. In our study, we regress the size quintiles excess returns $\left(r_{1}, r_{2}, r_{3}, r_{4}\right.$ et $\left.r_{5}\right)$ over the market portfolio and the predetermined variables. 
The returns of portfolios are calculated in excess of free risk rate ${ }^{4}$. It is defined in our study as the one-month Treasury bill. These values give the average risk premiums for the common factors in returns.

The market portfolio (PFMVW) is a value-weighted portfolio, which contains all the stocks of sample. Our choice is justified by the superior ability of this portfolio over others market indexes (CAC40, SBF250 SBF 120 and SBF 80) to capture the common variation of stock returns. The part 2 of the appendix 1 describes different regressions of excess stocks returns over the excess market portfolio returns and the predetermined variables. It shows that adjusted R-squared of all regressions with the market portfolio value weighted are higher than the regressions with other indexes. So, we use the market portfolio value weighted as a benchmark for the rest of regressions.

\section{A.2. the choice of the pertinent predetermined variables}

First, we test if the time series of all variables are stationary (see the Part 1 of appendix: table A, table B and their comments) and we conclude that the time series of variables dividend yield (DY), price to cash earning ratio (PCASH), book to market (BTMKT) and earning to price (PERINV) are non stationary. Consequently we will use differentiated time series of these variables for the rest of the paper.

Second we examine the matrix of correlation presented in the (table 1$)^{5}$. We remark that there is a weak correlation between variables of term spread (TERM) and of the default spread (DEFAULT) with the other predetermined variables. But there is a strong correlation between the valuation ratios of firms. For example, the correlation between the first difference of dividend yield (DDY) and the first difference of earning to price ratio (DPERINV) is equal to 0,784 . There is also the case of the first difference of the book to market ratio (DBTMKT) and the first difference of dividend yield (DDY) (their correlation is close to 0,767). Furthermore, the correlation between DPERINV and DBTMKT is relatively high and equal to 0,663 .

We also notice that the correlation between: DBTMKT and the first difference of price to cash earning ratio (DPCASH); DDY and DPCASH and finally DPERINV and DPCASH, is negative and higher than 0,1 in absolute value. For this reason we have to eliminate the redundant information variables, which are strongly correlated, and which have the weaker explanatory power in our model.

\footnotetext{
${ }^{4} r_{i t}=\left[\left(P_{i t}-P_{i t-1}+D_{i t}\right) / P_{i t}\right]-r_{f}$ with $P_{i t}$ is the price of security $i$ at time $t . P_{i t-1}$, is the price of security $i$ at time $t-1 . D_{i t}$ is the dividend of security $i$ distributed at time $t$ and $r_{f}$ is an interest free rate.

${ }^{5}$ Presented in the next page.
} 
For this reason, in first step, we have made a principal component analysis presented in the appendix 1 (Part 3) to study the relation between the ex-ante variables. We find that DDY, DPERINV and DBTMKT have almost the same coefficients in the first component. So they are very dependant variables and they should include the same contain of countable information. For that, it is interesting to choose only one variable of them.

In the second step, in order to include only the relevant variables in our model, we regress all the excess returns of the portfolios on each ex-ante variable, and then we examine their significance by the individual $\mathrm{t}$-statistics (see the table 2).

Table 1. The matrix of correlations between the explicative variables

\begin{tabular}{|l|r|l|l|l|l|l|l|}
\hline & PFMVW & TERM & DEFAULT & DDY & DPERINV & DPCASH & DBTMKT \\
\hline PFMVW & 1 & & & & & & \\
\hline TERM & 0,00987 & 1 & & & & & \\
\hline DEFAULT & $-0,12442$ & 0,05964 & 1 & & & & \\
\hline DDY & $-0,04496$ & $-0,0508$ & 0,11892 & 1 & & & \\
\hline DPERINV & $-0,09691$ & $-0,03$ & 0,10032 & 0,78428 & 1 & & \\
\hline DPCASH & 0,0573 & $-0,0685$ & $-0,1442$ & $-0,1217$ & $-0,1354$ & 1 & \\
\hline DBTMKT & $-0,04746$ & $-0,0483$ & 0,06966 & 0,76746 & 0,66293 & $-0,1075$ & 1 \\
\hline
\end{tabular}

Table 2. Summary statistics of regressions of dependant variables on ex ante variables

\begin{tabular}{|c|c|c|c|c|c|c|c|c|c|c|c|c|}
\hline \multirow{2}{*}{$\begin{array}{l}\text { Size } \\
\text { quintile }\end{array}$} & \multicolumn{3}{|c|}{$D D Y_{t-1}$} & \multicolumn{3}{|c|}{ DPERINV } & \multicolumn{3}{|c|}{$D B T M K T_{t-1}$} & \multicolumn{3}{|c|}{$D P C A S H_{t-1}$} \\
\hline & $\alpha$ & $\beta$ & $\overline{\mathrm{R}^{2}}$ & $\alpha$ & $\beta$ & $\overline{\mathrm{R}^{2}}$ & $\alpha$ & $\beta$ & $\mathrm{R}^{2}$ & $\alpha$ & $\beta$ & $\mathrm{R}^{2}$ \\
\hline 1 & $\begin{array}{l}0,0199 \\
(7,056)\end{array}$ & $\begin{array}{l}-0,022 \\
(-2,429)\end{array}$ & 0,0164 & $\begin{array}{l}0,006 \\
(4,289)\end{array}$ & $\begin{array}{l}-0,182 \\
(-0,858)\end{array}$ & 0,002 & $\begin{array}{l}0,019 \\
(7,03)\end{array}$ & $\begin{array}{l}-0,085 \\
(-2,16)\end{array}$ & 0,013 & $\begin{array}{l}0,0199 \\
(7,039)\end{array}$ & $\begin{array}{l}\text { E-04 } \\
(1,274)\end{array}$ & 0,0045 \\
\hline 2 & $\begin{array}{l}0,0228 \\
(2,89)\end{array}$ & $\begin{array}{l}-0,032 \\
(-1,223)\end{array}$ & $\overline{0,0042}$ & $\begin{array}{l}0,023 \\
(2,889)\end{array}$ & $\begin{array}{l}-1,694 \\
(-1,45)\end{array}$ & $\overline{0,0059}$ & $\begin{array}{l}0,023 \\
(2,889)\end{array}$ & $\begin{array}{l}-0,06 \\
(-0,58)\end{array}$ & $\overline{0,0009}$ & $\begin{array}{l}0,023 \\
(2,9)\end{array}$ & $\begin{array}{l}-0,0006 \\
(-0,837)\end{array}$ & 0,002 \\
\hline 3 & $\begin{array}{l}0,011 \\
(5,445)\end{array}$ & $\begin{array}{l}-0,019 \\
(-2,79)\end{array}$ & 0,0215 & $\begin{array}{l}0,0115 \\
(5,5)\end{array}$ & $\begin{array}{l}-1,3 \\
(-4,207)\end{array}$ & 0,048 & $\begin{array}{l}0,0115 \\
(5,429)\end{array}$ & $\begin{array}{l}-0,088 \\
(-2,97)\end{array}$ & 0,024 & $\begin{array}{l}0,0116 \\
(5,427)\end{array}$ & $\begin{array}{l}\text { 2E-04 } \\
(1,2)\end{array}$ & 0,004 \\
\hline 4 & $\begin{array}{l}0,009 \\
(4,45)\end{array}$ & $\begin{array}{l}-0,003 \\
(-0,43)\end{array}$ & 0,0005 & $\begin{array}{l}0,0094 \\
(4,452)\end{array}$ & $\begin{array}{l}-0,496 \\
(-1,589)\end{array}$ & 0,007 & $\begin{array}{l}0,009 \\
(4,45)\end{array}$ & $\begin{array}{l}-0,0004 \\
(-0,01)\end{array}$ & $1 \mathrm{E}-06$ & $\begin{array}{l}0,009 \\
(4,462)\end{array}$ & $\begin{array}{l}\text { E-04 } \\
(1,187)\end{array}$ & 0,004 \\
\hline 5 & $\begin{array}{l}0,006 \\
(4,295)\end{array}$ & $\begin{array}{l}-0,0002 \\
(-0,043)\end{array}$ & 5E-06 & $\begin{array}{l}0,006 \\
(4,289)\end{array}$ & $\begin{array}{l}-0,182 \\
(-0,859)\end{array}$ & 0,002 & $\begin{array}{l}0,006 \\
(4,28)\end{array}$ & $\begin{array}{l}-0,009 \\
(-0,491)\end{array}$ & $\overline{0,0006}$ & $\begin{array}{l}0,006 \\
(4,302)\end{array}$ & $\begin{array}{l}0,00015 \\
(1,267)\end{array}$ & $\overline{0,0045}$ \\
\hline
\end{tabular}

The table 2 presents regressions with the form: $r_{P t}=\alpha+\beta X_{t-1}$ with $X_{t-1}$ is the ex ante variable. All the regressions are estimated using ordinary least square (OLS). The ex ante variables are defined as follow: $D D Y_{t-1}$ is the first difference of a lagged value dividend yield of a value weighted stock index; $D P E R I N V_{t-1}$, is the first difference of a lagged value earning to price ratio of a value -weighted stock index; $D B T M K T_{t-1}$ is a lagged value book to market of a value weighted stock index and $D P C A S H_{t-1}$ is the first difference of a lagged value price to cash earning ratio of a value weighted stock index. The dependant variables are the excess returns of five quintile portfolios ranked by size. The first quintile is formed with the smallest firms and the fifth quintile is formed with the biggest ones. In this table we report the $\alpha, \beta$ and their t-statistics in parentheses and adjusted $\mathrm{R}$-squared. 
From table 2, we remark that all regressions of the excess returns of size portfolios (quintile 2, 4 and 5) on the ex ante variables have the slopes (of betas) significantly close to zero. Indeed, all the individual $\mathrm{t}$-statistics of 8 are inferior to 1,96 in absolute value (1,96 is the approximate theoretical value of t-student at a level of confidence 5\%). Moreover, we note that the R-squared is very low in these regressions.

Nevertheless, for the portfolios of small size firms (quintile 1) and medium size firms (quintile 3 ), the regression of excess stock returns on ex ante variables shows that the variables $D D Y_{t-1}$ and $D B T M K T_{t-1}$, have a significant coefficients $\beta$. But we notice that the variable $D P C A S H_{t-1}$ is not significant in all regressions and that DPERINV ${ }_{t-1}$, is significant only in the case of medium size firm regression.

From these results, we can retain the first difference of dividend yield or the first difference of book to market in addition to other macroeconomic predetermined variables: TERM and DEFAULT and we eliminate earning to price and price to cash earning ratios.

With the reference to precedent studies about US stock returns predictability (see Fama and French (1988a, 1989), Campbell and Shiller (1988), among others), dividend yield is a variable that is able to capture common variation in stock returns for the US market. Moreover, it is correlated with the inverse of price level of common stocks (see Keim and Stambaugh (1986)). So, for the rest of this paper, we will include as the predetermined variables: TERM, DEFAULT and $\mathrm{DDY}^{6}$. This conclusion excludes the other valuation ratios from the model because they are much correlated and not very able to predict common variation of stock returns in the time series regressions but they could capture predictability in cross section regressions.

\section{A.3. Descriptive statistics of variables}

The table 3 presents the descriptive characteristics of dependant and independent variables. We notice that the portfolio of small firms has the highest average excess return: it is about $2 \%$ with a standard deviation of 5,3\%. However the portfolio of big firms has the smallest one: it is about $0,6 \%$ with a standard deviation of $2,7 \%$. This finding supports the evidence of size effect as defined by Fama and French (1993). Indeed, they note that small firms generate a greater average excess returns than big firms.

\footnotetext{
${ }^{6}$ In the future research we will replace the value of DDY by BTMKT and we will study the stock return predictability including the variables TERM, DEFAULT and BTMKT.
} 
Table 3. The descriptive characteristics of dependant and explanatory variable

\begin{tabular}{|l|l|l|l|l|l|l|}
\hline & $r_{1}$ & $r_{2}$ & $r_{3}$ & $r_{4}$ & $r_{5}$ & PFMVW \\
\hline Mean & 0,0199 & 0,02296 & 0,0116 & 0,0094 & 0,0061 & 0,0083 \\
\hline Median & 0,0149 & 0,01059 & 0,0109 & 0,0061 & 0,0043 & 0,008 \\
\hline Maximum & 0,3567 & 2,56383 & 0,2299 & 0,2215 & 0,1153 & 0,139 \\
\hline Minimum & $-0,2107$ & $-0,1851$ & $-0,1712$ & $-0,1741$ & $-0,1117$ & $-0,11$ \\
\hline Std, Dev & 0,0533 & 0,14897 & 0,0403 & 0,0399 & 0,0269 & 0,0295 \\
\hline Skewness & 1,2845 & 14,4812 & 0,4927 & 0,2973 & 0,4364 & 0,3824 \\
\hline Kurtosis & 10,0552 & 242,245 & 7,0085 & 6,7992 & 5,2692 & 5,2163 \\
\hline J-Bera & 833,893 & 859052 & 252,043 & 218,737 & 87,4386 & 81,3154 \\
\hline Probability & 0 & & 0 & & 0 & 0 \\
\hline Obs & 0 & & 0 & 0 & 0 & 355 \\
\hline
\end{tabular}

\begin{tabular}{|l|l|l|l|l|l|l|}
\hline & TERM & DEFAULT & DDY & DPERINV & DPCASH & DBTMKT \\
\hline Mean & 0,0006 & $-0,0015$ & $-0,0036$ & $-8,4 \mathrm{E}-05$ & 0,0381 & $-0,0013$ \\
\hline Median & 0,0008 & $-0,0013$ & $-0,0207$ & $-0,0007$ & $-0,0002$ & $-0,0050$ \\
\hline Maximum & 0,0022 & 0,0134 & 1,8378 & 0,0327 & 77,1551 & 0,4628 \\
\hline Minimum & $-0,0031$ & $-0,0238$ & $-1,2584$ & $-0,0407$ & $-106,237$ & $-0,2864$ \\
\hline Std, Dev & 0,0009 & 0,0032 & 0,3046 & 0,0067 & 11,8635 & 0,0715 \\
\hline Skewness & $-0,8049$ & $-0,6939$ & 0,7010 & 0,1484 & $-1,2307$ & 1,3123 \\
\hline Kurtosis & 3,722 & 9,9859 & 8,092 & 8,6045 & 27,8583 & 12,6342 \\
\hline J-Bera & 46,0404 & 750,3798 & 412,609 & 465,926 & 9229,915 & 1474,8418 \\
\hline Probability & $1,01 \mathrm{E}-1$ & 0 & 0 & 0 & 0 & 0 \\
\hline Obs & 355 & 355 & 355 & 355 & 355 & 355 \\
\hline
\end{tabular}

\section{A.4. Regression results}

The table $4^{7}$ presents the results of regressions in which dependant variables are $\left(r_{1}, r_{2}, r_{3}\right.$, $r_{4}$ et $r_{5}$ ) and the explicative one is PFMVW. This regression is equivalent to the traditional CAPM model: $r_{P t}=\alpha_{P}+\beta_{P} P F M V W_{t}+\varepsilon_{p t}$

$r_{P t}$ is the excess return of portfolio $\mathrm{p}, r_{P t}=R_{P t}-R_{f t}$ where $R_{f t}$ is the return of one month treasury bill.

$P F M V W_{t}$ is the excess return of the market portfolio at time t.

$\beta_{P}$ : is the systematic risk of portfolio $\mathrm{p}$, it is defined as $\operatorname{cov}\left(r_{P t}, P F M V W\right) / \operatorname{var}(P F M V W)$

$\alpha_{P}$ : is the intercept of the equation.

$\varepsilon_{P t}:$ is the term of error.

In our model, we adopt these notations: $r_{i t}$ is identified to $r_{1 t}, r_{2 t}, r_{3 t}, r_{4 t}$ et $r_{5 t}$ while $r_{m t}$ is defined as $P F M V W_{t}$

\footnotetext{
${ }^{7}$ Presented in the next page.
} 
Table 4. Summary statistics of regressions of dependant variables $\left(r_{1}, r_{2}, r_{3}, r_{4}\right.$ et $\left.r_{5}\right)$ on market portfolio (PFMVW) : $r_{P t}=\alpha_{P}+\beta_{P} P F M V W_{t}+\varepsilon_{p t}$

\begin{tabular}{|l|l|l|l|}
\hline \multirow{2}{*}{ Size quintile } & \multicolumn{3}{|l|}{$P F M V W_{t}$} \\
\cline { 2 - 4 } & $\alpha$ & $\beta$ & Adjusted R \\
\hline $\mathbf{1}$ & 0,01 & 1,19 & 0,44 \\
& $(5,192)$ & $(9,16)$ & \\
\hline $\mathbf{2}$ & 0,004 & 2,327 & 0,21 \\
& $(1,35)$ & $(2,46)$ & \\
\hline $\mathbf{3}$ & 0,003 & 1,017 & 0,55 \\
& $(2,41)$ & $(10,48)$ & \\
\hline $\mathbf{4}$ & 0,002 & 1,12 & 0,69 \\
& $(0,171)$ & $(12,63)$ & \\
\hline $\mathbf{5}$ & $-0,0006$ & 0,814 & 0,8 \\
& $(-1,099)$ & $(13,76)$ & \\
\hline
\end{tabular}

This table presents, for each portfolio, the slopes and their t-statistics (between brackets). The t-statistics are corrected from heteroskedasticity by the matrix of White (1980). Adjusted $\mathrm{R}^{2}$ of time series regressions are presented in the last column.

The first observation from this table is that, adjusted R-squared is relatively low for the first regression on which the dependant variable is $r_{1}$, it is about $44 \%$. However it is equal to $80 \%$ in the last regression on which the dependant variable is $r_{5}$. Adjusted R-squared is a croissant function of the size quintile portfolio (excepting for the second portfolio of size). Moreover, in the first and third regressions, the constant is significantly different to zero with a t-statistic equal to $(5,192$ respectively 2,41$)$. In contrary, the constant is significantly close to zero in the second, forth and fifth regressions. The coefficients $\beta$ of the market portfolio excess returns are significant in all regressions (the t-statistics are much higher than 1,96 at level of confidence $5 \%$ ). So we conclude that the unconditional CAPM performs well in the case of firms with big size (alpha not significant, beta significantly different to zero and a high value of adjusted Rsquared). However, it is less pertinent in the case of small firms.

The table $5^{8}$ presents the results of regressions in which dependant variables are $\left(r_{1}, r_{2}, r_{3}\right.$, $r_{4}$ and $r_{5}$ ) and the independent ones are: PFMVW, TERM, DDY and DEFAULT. This regression has the form of the conditional CAPM model.

$r_{P t}=\alpha_{0 P}+\alpha_{1 P}$ TERM $_{t-1}+\alpha_{2 P} D D Y_{t-1}+\alpha_{3 P} D E F A U L T_{t-1}+\beta_{P} P F M V W_{t}+\varepsilon_{P t}$

\footnotetext{
${ }^{8}$ Presented in the next page
} 
Table 5. Summary statistics of regressions of dependant variables $\left(r_{1}, r_{2}, r_{3} r_{4}\right.$, et $\left.r_{5}\right)$ on explanatory variables PFMVW, TERM, DY and DEFAULT

\begin{tabular}{|c|c|c|c|c|c|c|c|}
\hline \multirow{2}{*}{$\begin{array}{l}\text { Size } \\
\text { quintile }\end{array}$} & \multirow[t]{2}{*}{$\alpha_{0}$} & $P F M V V$ & $\operatorname{TERM}_{t-1}$ & $D D Y_{t-1}$ & $D E F A U L T_{t-1}$ & \multirow[t]{2}{*}{ Adjusted $\mathrm{R}^{2}$} & \multirow[t]{2}{*}{ F-statistic } \\
\hline & & $\beta$ & $\alpha_{1}$ & $\alpha_{2}$ & $\alpha_{3}$ & & \\
\hline 1 & $\begin{array}{l}0,006 \\
(2,66)\end{array}$ & $\begin{array}{l}1,18 \\
(8,88)\end{array}$ & $\begin{array}{l}5,693 \\
(2,54)\end{array}$ & $\begin{array}{l}-0,016 \\
(2,39)\end{array}$ & $\begin{array}{l}-0,136 \\
(0,203)\end{array}$ & 0,45 & 73,54 \\
\hline 2 & $\begin{array}{l}0,014 \\
(1,44)\end{array}$ & $\begin{array}{l}2,36 \\
(2,42)\end{array}$ & $\begin{array}{l}-11,49 \\
(0,84)\end{array}$ & $\begin{array}{l}-0,025 \\
(2,05)\end{array}$ & $\begin{array}{l}1,93 \\
(1,22)\end{array}$ & 0,216 & 25,38 \\
\hline 3 & $\begin{array}{l}0,002 \\
(1,48)\end{array}$ & $\begin{array}{l}1,006 \\
(10,39)\end{array}$ & $\begin{array}{l}1,51 \\
(0,95)\end{array}$ & $\begin{array}{l}-0,014 \\
(3,03)\end{array}$ & $\begin{array}{l}0,13 \\
(0,29)\end{array}$ & 0,56 & 113,82 \\
\hline 4 & $\begin{array}{l}-3,6 \mathrm{E}-05 \\
(0,024)\end{array}$ & $\begin{array}{l}1,12 \\
(12,28)\end{array}$ & $\begin{array}{l}0,84 \\
(0,6)\end{array}$ & $\begin{array}{l}0,0017 \\
(0,47)\end{array}$ & $\begin{array}{l}0,23 \\
(0,65)\end{array}$ & 0,68 & 190,59 \\
\hline 5 & $\begin{array}{l}-0,001 \\
(1,33)\end{array}$ & $\begin{array}{l}0,81 \\
(13,49)\end{array}$ & $\begin{array}{l}0,415 \\
(0,48)\end{array}$ & $\begin{array}{l}0,003 \\
(1,66)\end{array}$ & $\begin{array}{l}-0,113 \\
(0,52)\end{array}$ & 0,79 & 350 \\
\hline
\end{tabular}

This table presents, for each portfolio, the slopes and their t-statistics (between brackets). The tstatistics are corrected from heteroskedasticity by the matrix of White (1980). Adjusted $\mathrm{R}^{2}$ and F-statistics of time series regressions are presented in the two last columns.

The first remark from this table, is that the conditional CAPM, in comparison with unconditional CAPM, has a little amelioration of adjusted R-squared for the portfolio of size 1, 2 and 3 (for example adjusted R-squared passes from 0,44 for size 1 with unconditional CAPM to 0,45 for size 1 with conditional CAPM). However, R-squared decreases slightly for the other sizes 4 and 5 .

Moreover, there is only one alpha that is significantly different to zero in the case of size 1 . (There are two alphas significantly different to zero in the case of unconditional CAPM). The slope of the market portfolio is significant for all sizes of firms.

We notice also that the coefficients of TERM have a t-statistics higher than two in absolute value in regression 1 (small size firms) but they are significantly close to zero in the other regressions. Furthermore, the variable DDY have a significant slope in the regressions 1, 2 and 3. However, the variable DEFAULT is not significant in all regressions. Consequently, the conditional CAPM model is more appropriate with the portfolios of small and medium size firms. In this case, we cannot reject the predetermined variables from the model. So, the evidence of predictability is verified in the French market for the small and medium stocks.

To verify if all the predetermined variables are significant or not in the conditional CAPM, we develop a test of the joint hypothesis that all the alpha coefficients are equal to zero: 
$\alpha_{0 P}=\alpha_{1 P}=\alpha_{2 P}=\alpha_{3 P}=0$. Indeed, to look if the regression is globally significant, we calculate F statistic of the regression 1,2,3,4 and 5 (see table 5). This statistics varies between 25,38 and 350. Then, we compare them to the $\mathrm{F}^{*}$ (theoretical value of $F_{(4,352)}^{0,05}$ ) which is equal to 2,37. Consequently, we notice that F-statistic is very much higher than its theoretical value and we conclude that the joint hypothesis is rejected and the alpha coefficients are globally significant in the regression. So that, we can affirm that the conditional CAPM performs also in the case of firms with big size and predetermined variables must be included in the regression.

To verify this global notice, we use the stepwise regression. This methodology consists of introducing or excluding successively, on at a time, the independent variables according to a criterion based on their marginal contribution in the regression. An explicative variable is eliminated from the model if it becomes superfluous following the addition of others variables at the previous stage. The regression stops entering independent variables when no of them can ameliorate the quality of regression.

The regressions 1' and 5' in the appendix (Stepwise regressions), are examples of step-by-step regressions which correspond to global regressions 1 (conditional CAPM in the case of small firms) and 5 (conditional CAPM in the case of big firms). From these regressions we draw the same conclusions as previous ones. But in regression 1', we remark that the first explicative variable is PFMVW. Then the model enters TERM and finally it addicts the variable DDY as significant variable in the model.

\section{A.5. The results of return predictability of risk premiums}

Our first objective in this study is to construct variables that might proxy for levels of asset prices and to investigate whether these variables predict risk premiums on a wide range of assets. Indeed, if expected returns change over time, particularly expected returns in excess of the riskless rate (risk premiums), and then asset pricing theories suggest that changes can be associated in part with changes in risk. For this reason we regress monthly risk premiums for each of portfolios (small stocks, medium stocks, big stocks and market) on the previous monthend value of the three ex-ante variables: TERM, DEFAULT and DDY. These regressions are used to identify the sources of time variation of risk premiums and consequently to study the predictability origins. Our regressions are similar to those used in the studies of Keim and Stambaugh (1986), Fama and French (1989), Ferson and Korajczyk (1995), among others. 
The table 6 presents the results of regressions in which dependant variables are $\left(r_{1}, r_{2}, r_{3}, r_{4}, r_{5}\right.$ and PFMVW) and the independent ones are: TERM, DDY and DEFAULT. The regressions are based on this equation: $r_{P t}=\gamma_{0 P}+\gamma_{1 P}$ TERM $_{t-1}+\gamma_{2 P} D D Y_{t-1}+\gamma_{3 P} D E F A U L T_{t-1}+u_{P t}$

Table 6: Summary statistics of regressions of dependant variables risk premiums $\left(r_{1}, r_{2}, r_{3}\right.$, $r_{4}, r_{5}$ and PFMVW) on the predetermined variables TERM, DDY and DEFAULT

\begin{tabular}{|c|c|c|c|c|c|c|}
\hline Size quintile & $\alpha_{0}$ & $\operatorname{TERM}_{t-}$ & $D D Y_{t-1}$ & $D E F A U L T_{t-1}$ & Adjusted $\mathrm{R}^{2}$ & F-statistics \\
\hline 1 & $\begin{array}{l}0,013 \\
(3,66)\end{array}$ & $\begin{array}{l}6,256 \\
(2,15)\end{array}$ & $\begin{array}{l}-0,019 \\
(2,117)\end{array}$ & $\begin{array}{l}-1,43 \\
(1,66)\end{array}$ & 0,027 & 4,319 \\
\hline 2 & $\begin{array}{l}0,028 \\
(2,74)\end{array}$ & $\begin{array}{l}-10,36 \\
(1,26)\end{array}$ & $\begin{array}{l}-0,03 \\
(1,24)\end{array}$ & $\begin{array}{l}-0,65 \\
(0,27)\end{array}$ & 0,0006 & 1,073 \\
\hline 3 & $\begin{array}{l}0,008 \\
(3,11)\end{array}$ & $\begin{array}{l}2 \\
(0,91)\end{array}$ & $\begin{array}{l}-0,017 \\
(2,55)\end{array}$ & $\begin{array}{l}-0,97 \\
(1,49)\end{array}$ & 0,021 & 3,564 \\
\hline 4 & $\begin{array}{l}0,007 \\
(2,49)\end{array}$ & $\begin{array}{l}1,38 \\
(0,62)\end{array}$ & $\begin{array}{l}-0,001 \\
(0,21)\end{array}$ & $\begin{array}{l}-1,001 \\
(1,5)\end{array}$ & $-0,0005$ & 0,939 \\
\hline 5 & $\begin{array}{l}0,004 \\
(2,09)\end{array}$ & $\begin{array}{l}0,8 \\
(0,52)\end{array}$ & $\begin{array}{l}0,001 \\
(0,24)\end{array}$ & $\begin{array}{l}-1,008 \\
(1,93)\end{array}$ & 0,007 & 1,8 \\
\hline PFMVW & $\begin{array}{l}0,006 \\
(2,89)\end{array}$ & $\begin{array}{l}0,477 \\
(0,27)\end{array}$ & $\begin{array}{l}-0,002 \\
(0,56)\end{array}$ & $\begin{array}{l}-1,098 \\
(2,21)\end{array}$ & 0,008 & 1,98 \\
\hline
\end{tabular}

From the table 6, we notice that the slopes of TERM and DDY in regression 1 (the case of small firms) are significantly different to zero. Indeed, they have a t-statistic higher than 1,96 in absolute values (at a level of confidence 5\%).

Moreover, the regression 3 (the case of medium size firms) shows that the variable DDY is significant in the model. So it can predict the premium risk of medium firms. In the regression with dependant variable PFMVW, the variable DEFAULT is also significant (it has a tstatistic value equal to $(-2,21))$. However, in the other regressions, we remark that the coefficients of predetermined variables are significantly close to zero at the level of confidence $5 \%$ (they have t-statistics inferior than 1,96 in absolute value). We conclude from these results that evidence of predictability of risk premium is verified for the case of small firms, medium firms and market portfolio. It appears to support the hypothesis that expected risk premiums change over time and that levels of asset prices contain information about expected premiums. The most important variable to capture common variation of small and medium stock returns is DDY. Moreover, we conclude that the risk premiums of portfolios of size 2 and 4 and 5 are not affected by the content of information included in ex ante variables. 
Indeed, their F-statistics are inferior to $\left(2,6\right.$ which is equal to $\left.F_{(3,352)}^{0,05}\right)$, so their regressions are globally not significant.

The adjusted R-squared of all regressions in the table 6 are very low. They vary between $-0,05 \%$ and $2,7 \%$.

Our results can be comparable with American studies. Indeed, to test predictable variation in the risk premiums, Keim and Stambaugh (1986) regress risk premiums on long-term bonds and common stocks. They find that the estimated coefficients on the three predetermined variables (the yield variable, the S\&P variable and the small firm variable) are positive for all assets and the t-statistics on these coefficients vary from 3,42 to 6,88 in the bond regressions and from 1,16 to 2,27 in the stock regressions.

A test of whether the coefficients are jointly equal zero across all the portfolios of stocks and bonds gives F-statistics between 8,17 and 11,4 with 7 and 2086 degrees of freedom, thereby, rejecting strongly equality to zero. Although the $\mathrm{R}$ squared values are typically only one to two percent.

Fama and French (1988) find an adjusted R-squared inferior than 10\% in regression of nominal and real CRSP value weighted NYSE portfolio returns on dividend yields. Ferson and Harvey (1991) find that the adjusted R-squared is near to $10 \%$ in regressions of the risk premiums on instrumental variables (dividend yield, equal weighted NYSE index return less one month Treasury bill return, default spread, term spread and nominal one month treasury bill rate).

Finally, we can conclude that in the French market, the conditional CAPM performs more in the case of small and medium stocks than in the case of big stocks. So the predictability in stock returns can generate abnormal returns based on the strategy of buying stocks of small and medium firms and selling those of big firms when it is expected that the variation in economic state will create investment opportunities.

\section{January effect}

Many earlier researchers conclude that January average returns are higher than in the other months and particularly for the small firms. Some ones have linked the abnormal returns associated with small capitalization to January effect. In the French market, many studies are interested with January effect (see Hamon (1986), Hamon and Jacquillat (1990, 1992), among others.). Indeed, Hamon and Jacquillat $(1990,1992)$ find that the firms with big capitalization generate superior returns than the small firms in the beginning of a year (month of January). This is related to the fiscal reasons (the small firms are undervalued in the end of a fiscal year to 
minimize impositions). However, in the other months of the year, the firms with small capitalization have superior returns than the firms with big capitalization.

In this subsection we will study January effect in French stock market. In table 7, we regress the portfolios excess returns on a dummy variable (noted JAN), which takes a value of one if the month is January and 0 otherwise. The regression has the form: $r_{P t}=\alpha+\beta J A N_{t}+\varepsilon_{P t}$

Table 7: regressions of the portfolios excess returns on the dummy variable $J A N_{t}$

\begin{tabular}{|c|c|c|c|c|c|}
\hline \multirow[t]{2}{*}{ Size quintile } & \multirow[b]{2}{*}{$\alpha$} & $J A N_{t}$ & \multirow[t]{2}{*}{$\begin{array}{l}\text { Adjusted } \\
\mathrm{R}^{2}\end{array}$} & \multirow{2}{*}{$\begin{array}{l}\text { Mean of } \\
\text { dependants } \\
\text { variables }\end{array}$} & \multirow[t]{2}{*}{$\begin{array}{l}\text { Standard deviation of } \\
\text { dependant variables }\end{array}$} \\
\hline & & $\beta$ & & & \\
\hline 1 & $\begin{array}{l}0,02 \\
(6,94)\end{array}$ & $\begin{array}{l}-0,01 \\
(0,986)\end{array}$ & $-0,000077$ & 0,0197 & 0,053 \\
\hline 2 & $\begin{array}{l}0,023 \\
(2,847)\end{array}$ & $\begin{array}{l}-0,01 \\
(0,359)\end{array}$ & $-0,002$ & 0,0225 & 0,149 \\
\hline 3 & $\begin{array}{l}0,011 \\
(5,03)\end{array}$ & $\begin{array}{l}0,0003 \\
(0,037)\end{array}$ & $-0,0028$ & 0,0113 & 0,04 \\
\hline 4 & $\begin{array}{l}0,0096 \\
(4,325)\end{array}$ & $\begin{array}{l}-0,0041 \\
(0,532)\end{array}$ & $-0,002$ & 0,009 & 0,04 \\
\hline 5 & $\begin{array}{l}-0,0066 \\
(4,39)\end{array}$ & $\begin{array}{l}-0,0067 \\
(1,31)\end{array}$ & 0,002 & 0,006 & 0,027 \\
\hline PF M V W & $\begin{array}{l}0,008 \\
(5,214)\end{array}$ & $\begin{array}{l}-0,0056 \\
(0,987)\end{array}$ & $-0,00007$ & 0,008 & 0,029 \\
\hline
\end{tabular}

Table 7 presents the averages and the standard deviations of portfolios excess returns. We notice that small firms have a higher average returns than the big ones, but they are more risky. The coefficients as measure the average returns of portfolios over the other months of the year different from January. The coefficients $\beta$ represent the difference of average returns between January month and the other months of the year (see Fama and French (1993)).

This table shows that all the coefficients of dummy variable are significantly close to zero at the level of confidence 5\% (for all regressions the t-statistics are inferior to 1,96 in absolute value). So we conclude that there is not a January effect for the French market. This conclusion is consisting with the finding of Lajili (2002). Indeed, she find also that all the coefficients of dummy variable are inferior than $2,5 \%$ per month with t-statistics inferior than two and that January effect is not verified in the case of French market. 


\section{Summary and conclusions}

The main conclusion to be drawn from our study is that expected risk premiums on French stock market appear to change over time in function of predetermined or lagged variables (a term premium: TERM, a default premium: DEFAULT and a first difference of dividend yield of a value weighted stock index: DDY) especially for the case of small and medium size firms. Consequently, the evidence of predictability of stock returns is also verified in the French market.

We have used time series regressions to study the relation between excess stocks returns and explicative variables and we have excluded at the beginning the ratios of valuation of firms because they were much correlated to each other and they are not very significant in the global regression. This result is not surprising because valuation ratios could be more significant in capturing common variation in stock premiums if they were used in cross section regressions. We find also that the traditional CAPM performs more in the case of big firms than in the case of small firms. However, the conditional CAPM is more pertinent in regressions with excess returns of small and medium firm portfolios.

Moreover, we have study the January effect in the French stock market and we have concluded that excess returns in month of January are not significantly different from the excess returns in other months of year.

In futures researches we should take into account the evidence of stock return predictability in the French market to study asset allocation, portfolio choice, asset pricing, performance measures, etc. 


\section{Appendix}

\section{Part 1.Tests of time series regressions}

In this part of appendix, we make different tests of time series regressions presented in this paper. First, we present the unit root tests, and then we develop the tests of homoskedasticity, autocorrelation and normality of residuals. Finally, we test the temporal stability of coefficients.

\section{Tests of stationary time series}

\section{I.1. Unit root tests}

We will use two unit root tests performed by Evious: the augmented Dickey-Fuller (ADF) test, and the Phillips-Perron (PP) test. Referring to Evious documentation, the Augmented Dickey-Fuller (ADF) Test controls for higher-order correlation by adding lagged difference terms of the dependent variable to the right-hand side of the regression. However, the Phillips-Perron (PP) Test controls for higher-order serial correlation in the series by making a correction to the t-statistic of the coefficient from the AR (1) regression to account for the serial correlation in.

Table A

\begin{tabular}{|l|l|l|l|l|}
\hline & \multicolumn{3}{|l|}{ ADF TEST } & \multicolumn{2}{l|}{ PP TEST } \\
\hline & Level & $\mathbf{1}^{\text {st }}$ difference & Level & $\mathbf{1}^{\text {st difference }}$ \\
\hline$r_{1}$ & $-7,547$ & - & $-16,566$ & - \\
\hline$r_{2}$ & $-7,988$ & - & $-18,698$ & - \\
\hline$r_{3}$ & $-8,244$ & - & $-15,379$ & - \\
\hline$r_{4}$ & $-7,722$ & - & $-17,634$ & - \\
\hline$r_{5}$ & $-6,939$ & - & $-16,497$ & - \\
\hline PFMVW & $-7,039$ & - & $-17,145$ & - \\
\hline TERM & $-4,306$ & - & $-4,018$ & - \\
\hline DEFAULT & $-6,413$ & - & $-16,428$ & - \\
\hline DY & $-2,226$ & $-8,359$ & $-2,576$ & $-17,767$ \\
\hline PCASH & $-2,145$ & $-8,923$ & $-2,082$ & $-16,883$ \\
\hline BTMAKT & $-2,426$ & $-8,7$ & $-2,92$ & $-17,819$ \\
\hline PERINV & $-2,802$ & $-9,28$ & $-3,454$ & $-17,216$ \\
\hline
\end{tabular}

The table A presents the two tests ADF and PP. We use tests with constant and trend and we consider that the number of lags is four. The critical value of MacKinnon, which rejects the null hypothesis of presence of a unit root with trend at a confidence level $1 \%$, is $-3,9878$ for the ADF test (versus -3,9876 for the PP test). The two tests reject the hypothesis of unit root with trend for the variables $r_{1}, r_{2}, r_{3}, r_{4}, r_{5}$, PFMVW, TERM and DEFAULT. Consequently, these series are stationary over the time. However, the variables DY, PCASH, BTMKT and PERINV have values of ADF and PP superior than the critical value. Thus, they are nonstationary over the time and we should use their first difference. Indeed, with the first difference of these variables, the null hypothesis is rejected and the differentiated series are stationary. 
I.2.Test of white noise of Ljung-Box (1978)

Table B

\begin{tabular}{|l|l|l|l|l|}
\hline & AC & PAC & Q-Stat & Prob \\
\hline$r_{1}$ & 0,145 & 0,145 & 7,577 & 0,006 \\
\hline$r_{2}$ & 0,007 & 0,007 & 0,018 & 0,892 \\
\hline$r_{3}$ & 0,201 & 0,201 & 14,512 & 0,001 \\
\hline$r_{4}$ & 0,074 & 0,074 & 1,986 & 0,159 \\
\hline$r_{5}$ & 0,138 & 0,138 & 6,817 & 0,009 \\
\hline PFMVW & 0,103 & 0,103 & 3,783 & 0,052 \\
\hline TERM & 0,926 & 0,926 & 308,39 & 0,00 \\
\hline DEFAULT & 0,328 & 0,328 & 38,656 & 0,00 \\
\hline DDY & 0,052 & 0,052 & 0,972 & 0,324 \\
\hline DPCASH & 0,107 & 0,107 & 4,107 & 0,043 \\
\hline DBTMKT & 0,091 & 0,091 & 0,938 & 0,333 \\
\hline DPERINV & 0,082 & 0,082 & 2,425 & 0,119 \\
\hline
\end{tabular}

Table B presents a test of white noise developed by Ljung-Box (1978).

The first two columns report the autocorrelation and the partial autocorrelation functions. The last two columns provide the Ljung-Box Q-statistics and their p-values. The Q-statistic at lag $\mathrm{k}$ is a test statistic for the null hypothesis that there is no autocorrelation up to order. The Qstatistic is often used as a test of whether the series is white noise. We fix the number of lags $\mathrm{k}$ at 1 .

We compare Q-statistic to $\chi^{2}(1 ; 1 \%)$ which is equal to 6,635 and we conclude that $r_{1}, r_{3}, r_{5}$, TERM and DEFAULT are not white noise.

\section{Tests of homoskedasticity}

White (1980) has derived a heteroskedasticity consistent covariance matrix estimator, which provides correct estimates of the coefficient covariance in the presence of heteroskedasticity. The null hypothesis, which is the absence of heteroskedasticity, is rejected if the LM statistic $\left(\mathrm{n} * \mathrm{R}^{2}\right)>\chi^{2}(\mathrm{p})$ at the level of confidence $\alpha . \mathrm{n}$ is the number of observations, $\mathrm{R}^{2}$ is the $\mathrm{R}$ squared and $\mathrm{p}=2 \mathrm{k}$ with $\mathrm{k}$ is the number of independent variables.

In our model with explicative variables: PFMVW, TERM, DEFAULT, DDY; $\chi^{2}(8)$ is equal to 20,09 at the level of confidence $1 \%$.

The table $C$ presents tests of homoskedasticity and shows the values of $\left(n * R^{2}\right)$ for all the dependant variables.

Table C

\begin{tabular}{|l|l|l|l|l|l|}
\hline & $r_{1}$ & $r_{2}$ & $r_{3}$ & $r_{4}$ & $r_{5}$ \\
\hline $\mathrm{N}^{*} \mathrm{R}^{2}$ & 90,3 & 165,76 & 126,92 & 181,55 & 193,1 \\
\hline
\end{tabular}

We notice that all the LM statistics are superior to the critical value of 20,09. So, the hypothesis of homoskedasticity is rejected and we correct estimates of the t-statistics with the matrix of White. 


\section{III.Tests of the residual autocorrelation (Durbin Watson (1950-1951) and Breusch- Godfrey (1988))}

We test the residual autocorrelation with reference to Durbin Watson (DW) and BreuschGodfrey (LM statistic $\left(n * R^{2}\right)$ ). The null hypothesis is independence of residuals.

Table D presents different tests of residual autocorrelation in the model with explicative variables PFMVW, TERM, DEFAULT, and DDY.

Table D

\begin{tabular}{|l|l|l|l|l|l|}
\hline & $r_{1}$ & $r_{2}$ & $r_{3}$ & $r_{4}$ & $r_{5}$ \\
\hline $\mathrm{DW}$ & 1,86 & 1,95 & 1,82 & 1,77 & 1,71 \\
\hline $\mathrm{N}^{*} \mathrm{R}^{2}$ & 10,52 & 0,59 & 3,75 & 4,42 & 8,06 \\
\hline
\end{tabular}

Table D accepts the null hypothesis that the residual are independents. Indeed, all the DW statistics are included in the interval $\left[\mathrm{d}_{2} ; 4-\mathrm{d}_{2}\right]$, which is $[1,74 ; 2,26]$. Moreover, all the LM statistics are inferior to $\chi^{2}(8)$ which is equal to 20,09 at the level of confidence $1 \%$.

\section{Tests of residual normality (Jarque-Bera (1984):(JB))}

\section{Table E}

Table E presents tests for residual normality in the model with explicative variables PFMVW, TERM, DEFAULT, and DDY.

\begin{tabular}{|l|l|l|l|l|l|}
\hline & $r_{1}$ & $r_{2}$ & $r_{3}$ & $r_{4}$ & $r_{5}$ \\
\hline JB & 615,55 & 773439,4 & 1251,07 & 1038,66 & 10190,67 \\
\hline
\end{tabular}

This table shows that the residual are not normal. Indeed, the statistics of JB have very high values.

\section{Tests of time series stability of chow coefficient}

Since, the period of study is relatively long; we make tests of time series stability. The tests of Chow are able to do this job. There are two tests: the Chow Break Point Test and the predictive test of Chow. The break point, which we use, is January 1989.

Table F presents the F-statistics and the probabilities for the two tests

Table F

\begin{tabular}{|l|l|l|l|l|}
\hline & \multicolumn{2}{|l|}{ Chow Break Point Test } & Predictive test of Chow \\
\hline & F-Statistic & Prob & F-Statistic & Prob \\
\hline$r_{1}$ & 5,9 & 0,00003 & 0,76 & 0,96 \\
\hline$r_{2}$ & 7,75 & 0,000001 & 29,67 & 0 \\
\hline$r_{3}$ & 5,47 & 0,000073 & 0,55 & 0,999958 \\
\hline$r_{4}$ & 8,41 & 0 & 0,89 & 0,77 \\
\hline$r_{5}$ & 2,1 & 0,064 & 0,62 & 0,999128 \\
\hline
\end{tabular}

We remark that most F-Statistic in the Chow Break Point Test are superior to $\mathrm{F}^{*}$ (theoretical value of $\mathrm{F}$ or $\left.F_{(4 ; 352)}^{0,05}\right)$ Which is equal to 2,37. So the hypothesis of stability of coefficients is rejected. Nevertheless, the predictive test of Chow shows positive results. Indeed, the predictive values of variables are close to their real values (probability close to 1 for most cases). 


\section{Part 2. Choice of the market portfolio}

The sample is composed of 527 French stocks. Five market portfolios $r_{m}$ are presented: the value weighted market portfolio (PFMVW), indices CAC40, SBF 250, SBF 120, and SBF 80. The dependant variables ${ }^{9}$ are $r_{1}$ and $r_{5}$. The explicative variables are the market portfolio $r_{m}$, TERM, DEFAULT and DDY. The period of study is $02 / 1991$ to $03 / 2004$. The following table shows the slopes and their t-statistics (between parentheses), and adjusted $\mathrm{R}^{2}$ of regressions. First, we regress monthly excess returns according the conditional CAPM as follow:

$$
r_{P t}=\alpha_{0 P}+\alpha_{1 P} \text { TERM }_{t-1}+\alpha_{2 P} D D Y_{t-1}+\alpha_{3 P} D_{E F A U L T}+\beta_{P} r_{m t}+\varepsilon_{P t}
$$

\begin{tabular}{|l|l|l|l|l|l|l|}
\hline & \multicolumn{5}{l|}{$r_{1}$} & Adjusted R $^{2}$ \\
\hline Market portfolio & $\alpha_{0 P}$ & \multicolumn{1}{l|}{$\beta_{P}$} & $\alpha_{1 P}$ & $\alpha_{2 P}$ & $\alpha_{3 P}$ & \\
\hline PFMVW & 0,009 & 0,79 & 4,95 & $-0,037$ & 0,09 & 0,2 \\
& $(2,92)$ & $(4,23)$ & $(2,05)$ & $(-2,88)$ & $(0,08)$ & \\
\hline SBF250 & 0,016 & 0,176 & 4,95 & $-0,03$ & $-0,14$ & 0,11 \\
& $(4,71)$ & $(3,41)$ & $(1,96)$ & $(-2,31)$ & $(-0,14)$ & \\
\hline SBF120 & 0,016 & 0,164 & 5,04 & $-0,03$ & $-0,15$ & 0,10 \\
& $(4,67)$ & $(3,26)$ & $(1,99)$ & $(-2,4)$ & $(-0,15)$ & \\
\hline SBF80 & 0,015 & 0,189 & 5,18 & $-0,03$ & $-0,1$ & 0,12 \\
& $(4,56)$ & $(3,7)$ & $(2,07)$ & $(-2,17)$ & $(-0,1)$ & \\
\hline CAC40 & 0,016 & 0,149 & 5 & $-0,03$ & $-0,17$ & 0,09 \\
& $(4,68)$ & $(3,07)$ & $(1,97)$ & $(-2,48)$ & $(-0,17)$ & \\
\hline
\end{tabular}

\begin{tabular}{|l|l|l|l|l|l|l|}
\hline & \multicolumn{5}{|l}{$r_{5}$} & Adjusted R $^{2}$ \\
\hline Market portfolio & $\alpha_{0 P}$ & \multicolumn{1}{l|}{$\beta_{P}$} & $\alpha_{1 P}$ & $\alpha_{2 P}$ & $\alpha_{3 P}$ & \\
\hline PFMVW & $-0,0009$ & 1,01 & 0,14 & 0,004 & 0,06 & 0,97 \\
& $(-2,34)$ & $(58,01)$ & $(0,54)$ & $(3,35)$ & $(0,68)$ & \\
\hline SBF250 & 0,008 & 0,224 & 0,196 & 0,009 & $-0,27$ & 0,36 \\
& $(5,32)$ & $(9,6)$ & $(0,17)$ & $(1,4)$ & $(-0,6)$ & \\
\hline SBF120 & 0,008 & 0,219 & 0,278 & 0,007 & $-0,275$ & 0,37 \\
& $(5,27)$ & $(9,75)$ & $(0,24)$ & $(1,18)$ & $(-0,61)$ & \\
\hline SBF80 & 0,007 & 0,19 & 0,58 & 0,01 & $-0,28$ & 0,26 \\
& $(4,6)$ & $(7,72)$ & $(0,47)$ & $(1,43)$ & $(-0,57)$ & \\
\hline CAC40 & 0,008 & 0,21 & 0,17 & 0,006 & $-0,28$ & 0,38 \\
& $(5,42)$ & $(9,96)$ & $(0,15)$ & $(0,98)$ & $(-0,64)$ & \\
\hline
\end{tabular}

\footnotetext{
${ }^{9}$ We have presented only the variables $r_{1}$ and $r_{5}$ to save space. The other results are available for request.
} 
Second we regress monthly excess returns according the unconditional CAPM as follow: $r_{P t}=\alpha_{P}+\beta_{P} r_{m t}+\varepsilon_{P t}$

\begin{tabular}{|l|l|l|l|}
\hline \multicolumn{1}{|l|}{} & $\alpha$ & $\beta$ & Adjusted R $^{2}$ \\
\hline & & & \\
\hline PFMVW & $\begin{array}{l}0,013 \\
(5)\end{array}$ & $\begin{array}{l}0,76 \\
(4,22)\end{array}$ & 0,15 \\
\hline SBF250 & $\begin{array}{l}0,02 \\
(6,86)\end{array}$ & $\begin{array}{l}0,19 \\
(3,71)\end{array}$ & 0,08 \\
\hline SBF120 & $\begin{array}{l}0,002 \\
(6,85)\end{array}$ & $\begin{array}{l}0,178 \\
(3,49)\end{array}$ & 0,072 \\
\hline SBF80 & $\begin{array}{l}0,02 \\
(6,75)\end{array}$ & $\begin{array}{l}0,2 \\
(4,02)\end{array}$ & 0,09 \\
\hline CAC40 & $\begin{array}{l}0,02 \\
(6,82)\end{array}$ & $\begin{array}{l}0,16 \\
(3,26)\end{array}$ & 0,06 \\
\hline
\end{tabular}

\begin{tabular}{|l|l|l|l|}
\hline \multicolumn{1}{|l|}{$r_{5}$} & $\alpha$ & $\beta$ & Adjusted R $^{2}$ \\
\hline & & & \\
\hline & & & \\
\hline PFMVW & $\begin{array}{l}-0,0008 \\
(-2,72)\end{array}$ & $\begin{array}{l}1,01 \\
(75,18)\end{array}$ & 0,97 \\
\hline SBF250 & $\begin{array}{l}0,008 \\
(6,56)\end{array}$ & $\begin{array}{l}0,221 \\
(9,6)\end{array}$ & 0,37 \\
\hline SBF120 & $\begin{array}{l}0,008 \\
(6,56)\end{array}$ & $\begin{array}{l}0,218 \\
(9,79)\end{array}$ & 0,38 \\
\hline SBF80 & $\begin{array}{l}0,008 \\
(5,887)\end{array}$ & $\begin{array}{l}0,18 \\
(7,67)\end{array}$ & 0,27 \\
\hline CAC40 & $\begin{array}{l}0,008 \\
(6,707)\end{array}$ & $\begin{array}{l}0,214 \\
(10,04)\end{array}$ & 0,39 \\
\hline & & & \\
\hline
\end{tabular}

\section{Part 3: Complementary regressions and analyses}

\section{Principal component analyses}

\begin{tabular}{|l|c|r|}
\hline & Initial & Extraction \\
\hline TERM & 1,00 &, 339 \\
\hline DEFAULT & 1,000 &, 440 \\
\hline DDY & 1,00 &, 876 \\
\hline DBTMKT & 1,00 &, 788 \\
\hline DPREINV & 1,00 &, 799 \\
\hline DPCASH & 1,00 &, 450 \\
\hline
\end{tabular}

Extraction Method: Principal Component Analyses.

Total Variance Explained

\begin{tabular}{|l|l|l|l|l|l|l|}
\hline & $\begin{array}{l}\text { Initial } \\
\text { Eigenvalues }\end{array}$ & & & $\begin{array}{l}\text { Extraction } \\
\text { Sums of } \\
\text { Squared } \\
\text { Loadings }\end{array}$ & & \\
\hline Component & Total & $\begin{array}{l}\text { \% of } \\
\text { Variance }\end{array}$ & Cumulative \% & & \\
\hline 1 & 2,532 & 42,198 & 42,198 & 2,532 & 42,198 & 42,198 \\
\hline 2 & 1,160 & 19,332 & 61,530 & 1,160 & 19,332 & 61,530 \\
\hline 3 &, 933 & 15,556 & 77,086 & & & \\
\hline 4 &, 855 & 14,244 & 91,330 & & & \\
\hline 5 &, 336 & 5,607 & 96,937 & & & \\
\hline 6 & 184 & 3,063 & 100,000 & & & \\
\hline
\end{tabular}

Extraction Method: Principal Component Analysis.

Component Matrix

\begin{tabular}{|l|l|l|}
\hline & Component & \\
\hline & 1 & 2 \\
\hline TERM & $-5,844 \mathrm{E}-02$ &, 579 \\
\hline DEFAULT &, 190 &, 635 \\
\hline DDY &, 932 & $-8,203 \mathrm{E}-02$ \\
\hline DBTMKT &, 880 &,- 116 \\
\hline DPREINV &, 892 & $-5,977 \mathrm{E}-02$ \\
\hline DPCASH &,- 230 &,- 630 \\
\hline
\end{tabular}

Extraction Method: Principal Component Analysis. A

2 components extracted. 


\section{Stepwise regressions}

\section{Regression $1^{\prime}$}

\section{Variables Entered/Removed}

\begin{tabular}{|c|l|l|l|}
\hline Model & $\begin{array}{l}\text { Variables } \\
\text { Entered }\end{array}$ & $\begin{array}{l}\text { Variables } \\
\text { Removed }\end{array}$ & Method \\
\hline 1 & PFMVW & & Stepwise (Criteria: Probability-of-F-to-enter $<=, 050$, Probability-of-F-to-remove $>=, 100)$. \\
\hline 2 & TERM & & Stepwise (Criteria: Probability-of-F-to-enter $<=, 050$, Probability-of-F-to-remove $>=, 100)$. \\
\hline 3 & DDY & & Stepwise (Criteria: Probability-of-F-to-enter $<=, 050$, Probability-of-F-to-remove $>=, 100)$. \\
\hline
\end{tabular}

a Dependent Variable: $r_{1}$

\section{Model Summary}

\begin{tabular}{|c|c|c|c|c|c|c|c|c|c|c|}
\hline & $\mathrm{R}$ & $\begin{array}{l}\mathrm{R} \\
\text { Square }\end{array}$ & $\begin{array}{l}\text { Adjuste } \\
\mathrm{d} \mathrm{R}\end{array}$ & $\begin{array}{l}\text { Std. Error of the } \\
\text { Estimate }\end{array}$ & $\begin{array}{l}\text { Change } \\
\text { Statistic }\end{array}$ & & & & & $\begin{array}{l}\text { Durbin- } \\
\text { Watson }\end{array}$ \\
\hline Model & & & & & \begin{tabular}{|l} 
R \\
Square
\end{tabular} & \begin{tabular}{|l|} 
F \\
Change
\end{tabular} & dfl & df2 & $\begin{array}{l}\text { Sig. F } \\
\text { Change }\end{array}$ & \\
\hline 1 & 0,661 & 0,436 & 0,435 & 0,0401450991382 &, 436 & 273,294 & 1 & 353 & 0,000 & \\
\hline 2 & 0,669 & 0,448 & 0,445 & 0,0397888089539 &, 012 & 7,350 & 1 & 352 & 0,007 & \\
\hline 3 & 0,676 & 0,457 & 0,452 & 0,0395300182677 &, 009 & 5,624 & 1 & 351 & 0,018 & 1,864 \\
\hline
\end{tabular}

a Predictors: (Constant), PFMVW

b Predictors: (Constant), PFMVW, TERM

c Predictors: (Constant), PFMVW, TERM, DDY

d Dependent Variable: $r_{1}$

\section{Coefficients}

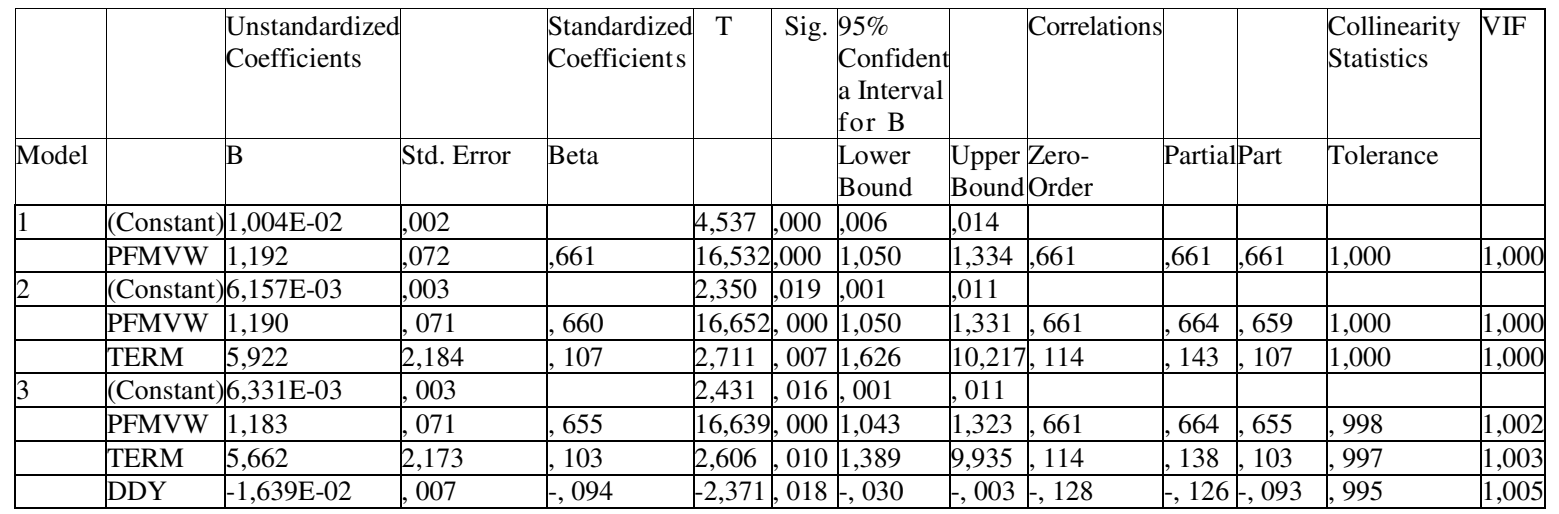

a Dependent Variable: $r_{1}$

\section{Excluded Variables}

\begin{tabular}{|c|c|c|c|c|c|c|c|c|}
\hline & & Beta In & $\mathrm{t}$ & & $\begin{array}{l}\text { Sig Partial } \\
\text { Correlatior }\end{array}$ & $\begin{array}{l}\text { Collinearity } \\
\text { nStatistics }\end{array}$ & & \\
\hline Model & & & & & & Tolerance & VIF & $\begin{array}{l}\text { Minimum } \\
\text { Tolerance }\end{array}$ \\
\hline 1 & DEFAULT &,- 013 &,- 313 &, 755 &,- 017 & 985 & 1,016 & 6,985 \\
\hline & DDY &,- 099 & $-2,486$ &, 013 &,- 131 & 998 & 1,002 & 2,998 \\
\hline & TERM &, 107 & 2,711 &, 007 & 143 & 1,000 & 1,000 & 01,000 \\
\hline 2 & DEFAULT &,- 019 &,- 483 & , 630 &,- 026 & ,981 & 1,020 & 0,981 \\
\hline & DDY &,- 094 & $-2,371$ & , 018 &,- 126 &, 995 & 1,005 & 5,995 \\
\hline 3 & DEFAULT &,- 008 &,- 208 &, 835 &,- 011 & ,967 & 1,034 & 4,967 \\
\hline
\end{tabular}

a Predictors in the Model: (Constant), PFMVW

b Predictors in the Model: (Constant), PFMVW, TERM

c Predictors in the Model: (Constant), PFMVW, TERM, DDY

d Dependent Variable: $r_{1}$ 


\section{Coefficient Correlations}

\begin{tabular}{|r|l|l|l|l|l|}
\hline Model & & & PFMVW & TERM & DDY \\
\hline 1 & Correlations & PFMVW & 1,000 & & \\
\hline & Covariances & PFMVW & $5,201 \mathrm{E}-03$ & & \\
\hline 2 & Correlations & PFMVW & 1,000 & 010 & \\
\hline & & TERM & 010 & 1,000 & \\
\hline & Covariances & PFMVW & $5,109 \mathrm{E}-03$ & $-1,541 \mathrm{E}-03$ & \\
\hline & & TERM & $-1,541 \mathrm{E}-03$ & 4,771 & \\
\hline 3 & Correlations & PFMVW & 1,000 &,- 008 & 045 \\
\hline & & TERM &,- 008 & 1,000 & 050 \\
\hline & & DDY & 045 & 050 & 1,000 \\
\hline & Covariances & PFMVW & $5,053 \mathrm{E}-03$ & $-1,175 \mathrm{E}-03$ & $2,188 \mathrm{E}-05$ \\
\hline & & TERM & $-1,175 \mathrm{E}-03$ & 4,721 & $7,574 \mathrm{E}-04$ \\
\hline & & DDY & $2,188 \mathrm{E}-05$ & $7,574 \mathrm{E}-04$ & $4,779 \mathrm{E}-05$ \\
\hline
\end{tabular}

a Dependent Variable: $r_{1}$

\section{Regression $5^{\prime}$}

Variables Entered/Removed

\begin{tabular}{|r|r|l|l|}
\hline Model & $\begin{array}{r}\text { Variables } \\
\text { Entered }\end{array}$ & $\begin{array}{l}\text { Variables } \\
\text { Removed }\end{array}$ & Method \\
\hline 1 & PFMVW & & Stepwise (Criteria: Probability-of-F-to-enter,- 050, Probability-of-F-to-remove $>=$, \\
\hline
\end{tabular}

a Dependent Variable: $r_{5}$

Model Summary

\begin{tabular}{|c|c|c|c|c|c|c|c|c|c|c|}
\hline & $\mathrm{R}$ & \begin{tabular}{|r|}
$\mathrm{R}$ \\
Square
\end{tabular} & $\begin{array}{l}\text { Adjusted } \\
\text { R Square }\end{array}$ & $\begin{array}{l}\text { Std. Error of } \\
\text { the Estimate }\end{array}$ & $\begin{array}{l}\text { Change } \\
\text { Statistics }\end{array}$ & & & & & $\begin{array}{l}\text { Durbin- } \\
\text { Watson }\end{array}$ \\
\hline Model & & & & & $\begin{array}{l}\text { R Square } \\
\text { Change }\end{array}$ & F Change & dfl & df 2 & $\begin{array}{l}\text { Sig. F } \\
\text { Change }\end{array}$ & \\
\hline 1 & 894 & 798 & & 798,012139476 & 798 & 1397,506 & 1 & 353 & 000 & 1,700 \\
\hline
\end{tabular}

a Predictors: (Constant), PFMVW

b Dependent Variable: $r_{5}$

\section{Coefficients}

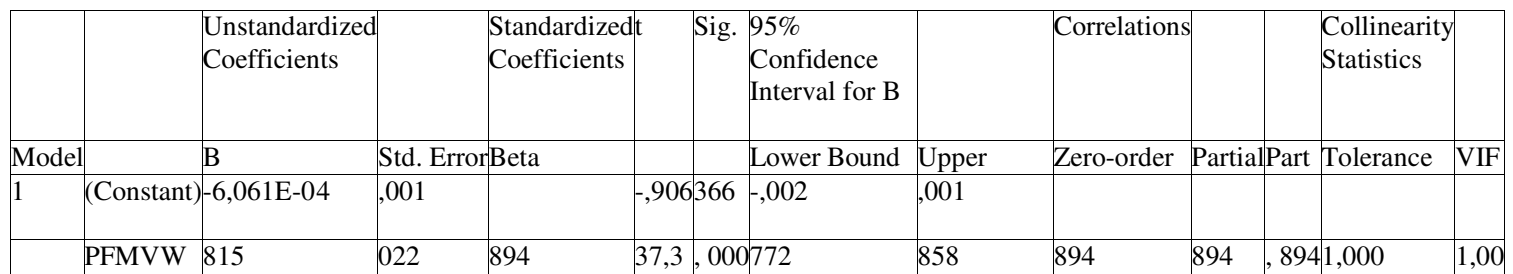

a Dependent Variable: $\mathbf{r}_{5}$

\section{Excluded Variables}

\begin{tabular}{|l|l|l|l|l|l|l|l|l|}
\hline & & & Beta InT & Sig. & $\begin{array}{l}\text { Partial } \\
\text { Correlation }\end{array}$ & $\begin{array}{l}\text { Collinearity } \\
\text { Statistics }\end{array}$ & & \\
\hline Model & & & & & & Tolerance & VIF & $\begin{array}{l}\text { Minimum } \\
\text { Tolerance }\end{array}$ \\
\hline 1 & DEFAULT-, 008 &,- 340 & 734 &,- 018 & 985 & 1,016985 \\
\hline & DDY & 038 & 1,588 & 113084 & 998 & 1,002998 \\
\hline & TERM & 012 & 503 & 615 & 027 & 1,000 & 1,000 & 1,000 \\
\hline
\end{tabular}

a Predictors in the Model: (Constant), PFMVW

b Dependent Variable $: r_{5}$

\section{Coefficient Correlations}

\section{Modèle PFMVW \\ Corrélations PFMVW 1,000 \\ Covariance PFMVW4,756 E-04}

Dependent Variable: $\mathbf{r}_{5}$ 


\section{References}

- Balvers.R, Cosimano.T and McDonald (1990) "Predicting stock returns in an efficient market" Journal of finance 45: 1109-1128.

- Basu.S (1977) "The investment performance of common stocks in relation to their price-earnings ratios: A test of the efficient markets hypothesis" Journal of finance 32: 663-682.

- Bekaert.G (2001) "Editor's Foreword to the special issue: On the predictability of asset returns" Journal of empirical finance 8, 451-457.

- Chen.N, Roll.R and Ross.S (1986) "Economic forces and the stock market" Journal of Business 59: 383-403.

- Chan.L, Hamao.Y and Lakonishok.J (1991) "Fundamentals and stock returns in Japan" Journal of finance 46: 1739-1764.

- Chan. L, Karceski.J and Lakonishok (1998) "The risk and return from factors" Journal of financial and quantitative analysis 33:159-188.

- Constantinides.G (1980) "Admissible uncertainty in the inter-temporel asset pricing model" Journal of financial and economics 8:71-86.

- Dybvig.P and Ross.S (1985) "Differential information and performance measurement using a security market line" Journal of finance 40: 383-399.

- Fama.E (1981) "Stock returns, real activity, inflation and money" American economic review 71: 545-565.

- Fama.E and French.K (1988 a) "Dividend yield and expected stock returns" Journal of financial economics 23: 3-25

- Fama.E and French.K (1988 b) "Permanent and temporary components of stocks prices" Journal of political economics 23: 3-25.

- Fama.E and French.K (1989) "Business conditions and expected returns on stocks and bonds" Journal of financial economics 25: 23-49.

- Fama.E and French.K (1992) "The cross-section of expected returns on stocks and bonds" Journal of financial economics 33: 3-56.

- Fama.E and French.K (1993) "Common risk factors in the returns on stocks and bonds" Journal of financial economics 33: 3-56.

- Fama.E and French.K (1996) "Multifactor explanations of asset pricing anomalies" Journal of finance 51: 55-87. 
- $\quad$ Fama.E (1991) "Efficient capital markets: II" Journal of finance 46: 1575 -1615.

- Ferson.W (1990) "Are latent variables in time-varying expected returns compensation for consumption risk?" Journal of finance 45: 397-430.

- Ferson.W and Harvey.C (1991) "The variation of economic risk premiums" Journal of political economy. 99:385-415.

- Ferson.W and Harvey.C (1998) "Fundamental determinants of national equity market returns: a perspective on conditional asset pricing" Journal of banking and finance 21: $1626-1965$.

- Ferson. W and Korajczyk (1995) "Do arbitrage pricing models explain the predictability of stock returns?" Journal of business 68: 309-348.

- Gibbons.M and Ferson.W (1985) "Tests of asset pricing models with changing expectations and unobservable market portfolio" Journal of financial economics 14: 217-236.

- Guerard.J.B and Takano.M (1990) "Composing modeling in the Japanese equity markets" working paper presented at the Berkeley program in finance.

- Hamon.J (1986) " Le caractère saisonnier des rentabilit6s mensuelles a la bourse de Paris", Finance 7: 57-74.

- Hamon.J and Jaquillat.B (1990) " Effet janvier et taille a la bourse de Paris" Cahiers de recherche CEREG, no.9012.

- Hamon.J and Jaquillat.B (1992), Le marché français des actions : Etudes empiriques 1977-1991, $1^{\text {ière }}$ Edition, Finance, ch.4,5,6,7, Edition PUF

- Jagannathan. R and Wang.Z (1996) "The conditional CAPM and cross-section of stock returns" Journal of finance 51: 3-53.

- Jensen M. (1968) "The performance of mutual funds in the period 1945-1964" Journal of Finance 23: 389- 416.

- Keim. D and Stambaugh. R (1986) "Predicting returns in the stock and bond markets" Journal of financial economics 17: 357-390.

- Kothari.S and Shanken. J (1996) "Book to market, dividend yield and expected market returns: a time series analysis" Journal of financial economics 44: 169-203.

- Lajili.S (2002) " The capital asset pricing model and the three factor model of Fama and French revisited in the case of France", Cahier de recherche du CEREG, University Paris Dauphine (2002), no. 2002-10, 1-26. 
- Lo. A and MacKinlay. A (1988) "Stock market prices do not follow random walks: evidence from a simple specification test" Review of financial studies 1: 41-66.

- Merton. R (1973) “An intertemporal capital asset pricing model” Econometrica 41: 867-887.

- Poterba.J and Summers.L (1986) "The persistence of volatility and stock market fluctuations" American economic review 76: 1142-1151.

- Pesaran. H (2003) "Market efficiency and stock market predictability" working paper (Mphil Subject 301).

- Rey.D (2004) "Stock market predictability: is it there? A critical review" Working paper $\mathrm{n}^{\circ} 12 / 03$, Version march 2004.

- Rozenberg.B, Reid.K and Lanstein. R (1985) " Persuasive evidence of market inefficiency" Journal of portfolio management 9-17

- $\quad$ Sharpe.W (1966) "Mutual Funds Performance" Journal of Business 39:119-138.

- Shiller and Perron.P (1985) "Testing the random walk hypothesis: power versus frequency of observation" Economics Letters 18: 381-386.

- Summers.L (1986) "Does the stock market rationally reflect fundamental values?" Journal of finance 41: 591-601.

- Wadhwani.S and Shah.M (1993) "Valuation indicators and stock market prediction: I. Working paper, Goldman Sachs International, Ltd., London. 